\title{
GMR
}

\section{Novel multiplex PCR for detection of diarrheagenic Escherichia coli strains isolated from stool and water samples}

\author{
J.W. Vendruscolo, T.L. Waldrich, G.I.A. Saikawa, J.S. Pelayo, \\ R.K.T. Kobayashi, G. Nakazato and S.P.D. Rocha \\ Departamento de Microbiologia, Centro de Ciências Biológicas, \\ Universidade Estadual de Londrina, Londrina, PR, Brasil \\ Corresponding author: S.P.D. Rocha \\ E-mail: rochaspd@uel.br
}

Genet. Mol. Res. 16 (3): gmr16039760

Received June 26, 2017

Accepted August 8, 2017

Published August 17, 2017

DOI http://dx.doi.org/10.4238/gmr16039760

Copyright $(92017$ The Authors. This is an open-access article distributed under the terms of the Creative Commons Attribution ShareAlike (CC BY-SA) 4.0 License.

\begin{abstract}
Diarrhea is considered the second most common cause of infant mortality worldwide. The disease can be caused by many different pathogens, including diarrheagenic Escherichia coli (DEC), which includes the pathotypes enterotoxigenic E. coli (ETEC), enteroinvasive E. coli (EIEC), enteroaggregative E. coli (EAEC), Shiga toxin-producing E. coli (STEC), and enteropathogenic E. coli (EPEC). To develop a multiplex PCR system for the safe and accurate identification of the five main pathotypes of DEC, seven pairs of primers were determined for the following genes: aaiC, escV, bfpA, ipaH, elt, stx 1 , and stx 2 . To validate the system, 413 isolates from different sources (water and both animal and human stool) were analyzed that had been characterized previously. The sensitivity data were grouped by pathotype, in which $92.7 \%$ of the atypical EPEC were correlated, as were $92.8 \%$ of the STEC, $91.35 \%$ of the EAEC, and $100 \%$ of the typical EPEC, ETEC, and EIEC. These findings indicate that it is possible to detect the major five pathotypes of DEC from different sources, which can aid in determining the epidemiology of diarrhea with a low cost,
\end{abstract}

Genetics and Molecular Research 16 (3): gmr16039760 
high sensitivity and specificity, and the easy and safe viewing of the resulting PCR products.

Key words: Multiplex PCR; Diarrheagenic Escherichia coli; Epidemiology; Diarrhea; Virulence

\section{INTRODUCTION}

Diarrhea, which is considered the second most common cause of infant mortality worldwide, is a neglected clinical manifestation, especially because of its labor-intensive microbiological diagnosis and epidemiology.

Escherichia coli diarrheagenic (DEC) pathotypes represent the dominant bacterial pathogens that are epidemiologically associated with diarrhea: enteropathogenic E. coli (EPEC), enteroinvasive E. coli (EIEC), Shiga-toxin producing E. coli (STEC), enterotoxigenic E. coli (ETEC), and enteroaggregative E. coli (EAEC) (Clements et al., 2012).

Because the virulence genes that characterize $E$. coli are genetically encoded by chromosome, pathogenicity islands, plasmids, and bacteriophages, it follows that polymerase chain reaction (PCR) would provide a reliable system for amplifying a specific region of DNA (Pass et al., 2000).

Several multiplex PCR systems for DEC detection have been developed; however, the analyses have been restricted to $E$. coli strains isolated from fecal samples from humans or animals (Pass et al., 2000; Rumi et al., 2012; Fujioka et al., 2013; Oh et al., 2014).

Considering the importance of DEC as the cause of diarrhea, the aim of this study was to perform a multiplex PCR assay to detect the five main pathotypes of DEC isolated from different sources, water and both human and animal feces. This technique can aid in epidemiological surveillance and control efforts in endemic areas.

\section{MATERIAL AND METHODS}

\section{Bacterial strains}

The strains used in this study were obtained from collections of the Bacteriology and Bacteriology Basic and Applied Laboratories of the State University of Londrina between 2012 and 2015. A total of 413 E. coli isolates were sampled from the following different sources: 189 from animal stools (cat, dog, and bovine), 54 from water, and 170 from human stools. Among these isolates, positivity for one or more DEC genes corresponded to 109 (57.7\%), 9 (16.7\%), and 65 isolates (38.2\%), respectively, and the total included 183 isolates of DEC and 230 isolates of nonpathogenic $E$. coli. This collection was characterized using the following primers: EAEC $(a g g R)$ (Boisen et al., 2012), EIEC (ipaH) (Aranda et al., 2007), STEC (stx1, stx2, and eae) (Paton and Paton, 1998), EPEC (eae and bfpA) (Gunzburg et al., 1995; Paton and Paton, 1998) and ETEC (elt) (Aranda et al., 2007). The E. coli DH5 $\alpha$ and other Enterobacteriaceae were used as negative controls: Shigella flexneri M90T, Salmonella enterica serovar Enteritidis ATCC 13076, Klebsiella pneumoniae ATCC 700603 K6, and Proteus mirabilis ATCC 7002.

\section{Multiplex PCR design}

Five primer sets were designed based on an analysis of gene sequences published

Genetics and Molecular Research 16 (3): gmr16039760 
in the National Center for Biotechnology Information (NCBI) database. The MPPrimer program (Shen et al., 2010) was used to obtain, analyze, and assess the specificity of the primer sequences. The following reference strains were used: EAEC 042 (GenBank accession No. FN554766.1), EIEC 53638 O144 (GenBank accession No. CP001064.1), EPEC O127:H6 (GenBank accession No. FM180569.1), and ETEC H104:O7 (GenBank accession No. EU113248.1). Additionally, two pairs of primers that had been previously described in the literature were used (stxl and stx2) (Leotta et al., 2005).

\section{Multiplex PCR assay}

The strains analyzed by PCR were grown on Luria-Bertani agar and incubated at $37^{\circ} \mathrm{C}$ for $24 \mathrm{~h}$. Bacterial DNA of 3 colonies was extracted by boiling. Multiplex PCRs were performed in a thermocycler (Veriti 96-Well Thermal Cycler, Applied Biosystems ${ }^{\mathrm{TM}}$, California, USA) to the following cycling conditions: $95^{\circ} \mathrm{C} / 5 \mathrm{~min}, 15$ cycles of $95^{\circ} \mathrm{C} / 1 \mathrm{~min}, 62^{\circ} \mathrm{C} / 2 \mathrm{~min}$, and $72^{\circ} \mathrm{C} / 2 \mathrm{~min}, 20$ cycles of $95^{\circ} \mathrm{C} / 1 \mathrm{~min}, 58^{\circ} \mathrm{C} / 2.5 \mathrm{~min}$, and $72^{\circ} \mathrm{C} / 1 \mathrm{~min}$ and final extension at $72^{\circ} \mathrm{C} / 7 \mathrm{~min}$. These conditions were used in all analyses and resulted in three multiplex PCR systems with a final volume of $25 \mu \mathrm{L}$ each (Table 1). PCR products were separated on $2.5 \%$ agarose gels $(70 \mathrm{~V})$ and assessed for potential differences after $1 \mathrm{~h}$ (Figure 1).

Table 1. Description of oligonucleotides and reagent concentrations used in the three systems.

\begin{tabular}{|c|c|c|c|c|c|c|}
\hline Target gene (GenBank accession No.) & Type of PCR & Primer sequence $\left(5^{\prime} \rightarrow 3^{\prime}\right)$ & Amplicon size (bp) & $\begin{array}{l}\text { Final concentration of } \\
\text { primers }(\mathrm{mM})\end{array}$ & Reagents of the system & Reference \\
\hline aaiC (FN554766.1) & System 1 & $\begin{array}{l}\text { AGAGCGTCCACTGTCAGAGCGT } \\
\text { GCGACCTGCTCTGGCGTGAAAT }\end{array}$ & 183 & 400 & $\begin{array}{l}\text { Buffer: } 1 \mathrm{X} \\
\mathrm{MgCl}_{2}: 2.2 \mathrm{mM} \\
\text { dNTP: } 0.46 \mathrm{mM} \text { each } \\
\text { Tag polymerase: } 2.5 \mathrm{U}\end{array}$ & This study \\
\hline escV (FM180568.1) & System 1 & $\begin{array}{l}\text { TAACGCCTGCGCGCATATCACC } \\
\text { GTTGATGCGCCTGTCGCTAGT }\end{array}$ & 266 & 400 & & This study \\
\hline bfpA (FM180569.1) & System 1 & $\begin{array}{l}\text { TCTGCAATGGTGCTTGCGCTTG } \\
\text { CAGTTGCCGCTTCAGCAGGAGT }\end{array}$ & 478 & 480 & & This study \\
\hline $\operatorname{stxl}(\mathrm{JX} 206444.1)$ & System 2 & $\begin{array}{l}\text { AGCGATGCAGCTATTAATAA } \\
\text { GAAGAGTCCGTGGGATTACG }\end{array}$ & 130 & 480 & \multirow{2}{*}{$\begin{array}{l}\text { Buffer: } 1 \mathrm{X} \\
\text { MgCl: } 2.2 \mathrm{mM} \\
\text { dNTP: } 0.46 \mathrm{mM} \text { each } \\
\text { Taq polymerase: } 3 \mathrm{U}\end{array}$} & Leotta et al., 2005 \\
\hline ipaH (CP001064.1) & System 2 & $\begin{array}{l}\text { CAGGTGGCTGCATGGCTGGAAA } \\
\text { GGCAGTGCGGAGGTCATTTGCT }\end{array}$ & 383 & 480 & & This study \\
\hline stx2 (AY633471.1) & System 3 & $\begin{array}{l}\text { TTAACCACACCCCACCGGGCAGT } \\
\text { GCTCGGATGCATCTCTGGT }\end{array}$ & 346 & 560 & \multirow{2}{*}{$\begin{array}{l}\text { Buffer: } 1 \mathrm{X} \\
\text { MgCl: } 2.2 \mathrm{mM} \\
\text { dNTP: } 0.46 \mathrm{mM} \text { each } \\
\text { Taq polymerase: } 3 \mathrm{U}\end{array}$} & Leotta et al., 2005 \\
\hline Elt (EU113248.1) & System 3 & $\begin{array}{l}\text { AGGCGTATACAGCCCTCACCCA } \\
\text { ACCTGAAATGTTGCGCCGCTCT }\end{array}$ & 550 & 480 & & This study \\
\hline
\end{tabular}

Genes and pathotypes: aaiC (EAEC), escV (atypical EPEC), escV and bfp A (typical EPEC); escV and stx1 and/or stx2 (Enterohemorrhagic Eschericchia coli, EHEC); stx1 and/or stx2 (STEC); ipaH (EIEC); and elt (ETEC).
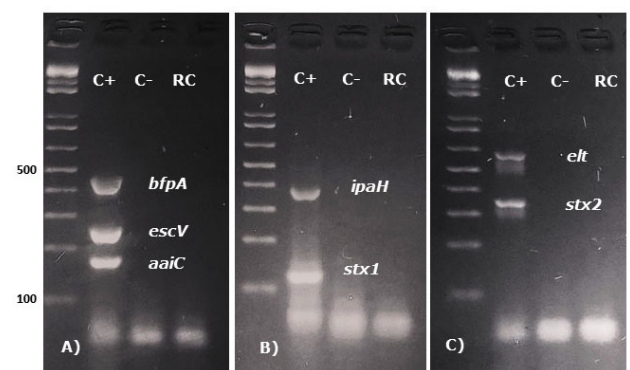

Figure 1. Profile electrophoretic of the specific loci amplified in multiplex PCR systems 1, 2, and 3 on a $2.5 \%$ agarose gel. A. System mPCR1 genes: $b f p A$, escV, and aaiC. B. System mPCR2 genes: $i p a H$ and $s t x 1$. C. System mPCR3 genes: elt and stx2. C+: positive control (A) EPEC O127:H6 and EAEC 042; (B) EIEC 53638 O144 and EHEC EDL933; (C) ETEC H104:O7 and EHEC EDL933. C- negative control (E. coli DH5 $\alpha$ ). RC: reaction control (no DNA). 


\section{Sensitivity of the multiplex PCR}

To verify the sensitivity of the multiplex PCR, serial 10 -fold dilutions of bacterial DNA were performed. Then, the dilutions were subjected to multiplex PCR assay.

\section{RESULTS}

All primers were shown to be specific for the respective patterns of E. coli, with a minimum sensitivity of $5.2 \mathrm{ng} / \mu \mathrm{L}$. For other Enterobacteriaceae strains verified, the ipaH gene was positive for $S$. flexneri.

The results were compared to previously conducted analyses based on the presence of specific genes for each pathotype. This analysis indicated that 183 strains had DEC-positive results, whereas positivity was detected in 160 isolates when using novel multiplex PCR system. Of these, 88 isolates were isolated from animal stool samples, 45 were from human stool samples, and 27 were from water samples (Table 2).

According to comparisons between the pretest identities and the results of our multiplex PCR (Table 2), for atypical EPEC, the sensitivity reached $91.3 \%$ for the isolates from the animal stool, $86.7 \%$ for the human stool, and $100 \%$ for water. For STEC strains, the sensitivity reached $81.7 \%$ for the animal stool, $86.7 \%$ for the human stool, and $100 \%$ for water samples. The sensitivity for typical EPEC, ETEC, and EIEC strains was $100 \%$.

Table 2. Comparison between the collection and novel multiplex PCRs.
\begin{tabular}{l|c|c|c|c|c|c}
\hline \multirow{2}{*}{ Pathotype } & Collection & & \multicolumn{3}{c}{ Multiplex PCR } \\
\cline { 2 - 7 } & Water & Human stool & Animal stool & Water & Human stool & Animal stool \\
\hline aEPEC & 6 & 15 & 23 & 6 & 13 & 21 \\
\hline tEPEC & - & 10 & - & - & 10 & - \\
\hline EIEC & - & - & 2 & - & 2 & 31 \\
\hline STEC & 3 & 3 & 60 & 3 & 20 & 21 \\
\hline EAEC & - & 37 & 11 & 18 & - & 13 \\
\hline ETEC & - & - & 13 & - & 45 & 88 \\
\hline Positive & 9 & 65 & 109 & 27 & 125 & 101 \\
\hline Negative & 45 & 105 & 80 & 27 & & 170 \\
\hline Total (isolates) & 54 & 170 & 189 & 54 & & 189 \\
\hline
\end{tabular}

aEPEC $=$ atypical EPEC; tEPEC $=$ typical EPEC.

\section{DISCUSSION}

The molecular details of virulence factors have been extensively studied and characterized, thus enabling their possible applications in epidemiology studies. However, the genetic diversity of DEC strains makes the identification of species labor-intensive and involves a series of molecular tests to precisely define the pathotype involved in an infection.

The present study aimed to develop this tool to be capable of differentiating among the five main DEC categories by using 7 pairs of primers in 3 different systems with the same programming thermocycler. This would allow the possibility of analyzing strains of different origins by visualizing PCR products by agarose gel electrophoresis, maintaining good resolvability between the PCR products to ensure that the visualization of the results was unambiguous. Fujioka et al. (2013) reported the development of a multiplex PCR to sort 10 genes into five main categories of DEC in a single reaction, but the visualization of results was affected by not achieving a safe distance between the PCR products.

Genetics and Molecular Research 16 (3): gmr16039760 
Moreover, this study aimed to allow different strains that were isolated from different sources (water, and both human and animal feces) to be analyzed. Different multiplex PCR systems for DEC detection have been developed; however, the analyses have been restricted to fecal samples from humans or animals or did not distinguish among the five major classes of DEC and required other PCRs to verify the results (Pass et al., 2000; Rumi et al., 2012; Fujioka et al., 2013; Oh et al., 2014).

The heterogeneity of the results of STEC present by us is likely indicated by the genetic variability for stx2 (Paton and Paton, 1998). About stx2 our intention was to detect the gene and not the specific subtype. We tested four different set of primers, two designed by us and two from literature (data not shown). The primer set described by Leotta et al. (2005) presented the best sensitivity and was used by us.

Our system recognized $100 \%$ of typical EPEC, ETEC, and EIEC. These findings demonstrate that the target genes probably do not have much variability in the sequence. Although the occurrence for these pathotypes was low, its importance is indicated by the occurrence of outbreaks (Ochoa et al., 2008).

For searches of EAEC strains, the collection of laboratories was chosen for the application of primers for $\operatorname{agg} R$ to detect this pathotype. This study opted to study a chromosomal gene (aaiC). As shown by Lima et al. (2013) the aaiC gene is a good candidate for molecular diagnosis because it has a chromosomal origin and is more prevalent that plasmid genes in EAEC. Our findings for aaiC and $a g g R$ revealed that the difference between the molecular diagnosis of chromosomal and plasmid genes was 59 strains positive for aaiC and only 48 for $\operatorname{agg} R$ (Table 2).

Therefore, the findings indicate that there is a possibility to detect the major 5 pathotypes of DEC from different sources, which may aid in assessments of the epidemiology of diarrhea, with low cost, high sensitivity and specificity, and the easy and safe viewing of PCR products.

\section{ACKNOWLEDGMENTS}

The authors thank the State University of Londrina for the scholarship to G.I.A. Saikawa, Coordenação de Aperfeiçoamento de Pessoal de Nível Superior (CAPES) for the scholarship to J.W. Vendruscolo, and Fundação Araucária (Agreement PPSUS \#04/2013) and FAEPE/UEL - PUBLIC 2016 for financial support.

\section{REFERENCES}

Aranda KR, Fabbricotti SH, Fagundes-Neto U and Scaletsky IC (2007). Single multiplex assay to identify simultaneously enteropathogenic, enteroaggregative, enterotoxigenic, enteroinvasive and Shiga toxin-producing Escherichia coli strains in Brazilian children. FEMS Microbiol. Lett. 267: 145-150. https://doi.org/10.1111/j.1574-6968.2006.00580.x

Boisen N, Scheutz F, Rasko DA, Redman JC, et al. (2012). Genomic characterization of enteroaggregative Escherichia coli from children in Mali. J. Infect. Dis. 205: 431-444. https://doi.org/10.1093/infdis/jir757

Clements A, Young JC, Constantinou N and Frankel G (2012). Infection strategies of enteric pathogenic Escherichia coli. Gut Microbes 3: 71-87. https://doi.org/10.4161/gmic.19182

Fujioka M, Otomo Y and Ahsan CR (2013). A novel single-step multiplex polymerase chain reaction assay for the detection of diarrheagenic Escherichia coli. J. Microbiol. Methods 92: 289-292. https://doi.org/10.1016/j.mimet.2012.12.010

Gunzburg ST, Tornieporth NG and Riley LW (1995). Identification of enteropathogenic Escherichia coli by PCR-based detection of the bundle-forming pilus gene. J. Clin. Microbiol. 33: 1375-1377.

Leotta GA, Chinen I, Epszteyn S, Miliwebsky E, et al. (2005). Validation of a multiplex PCR for detection of Shiga toxin-

Genetics and Molecular Research 16 (3): gmr16039760 
producing Escherichia coli. Rev. Argent. Microbiol. 37: 1-10.

Lima IFN, Boisen N, Quetz JdaS, Havt A, et al. (2013). Prevalence of enteroaggregative Escherichia coli and its virulencerelated genes in a case-control study among children from north-eastern Brazil. J. Med. Microbiol. 62: 683-693. https://doi.org/10.1099/jmm.0.054262-0

Ochoa TJ, Barletta F, Contreras C and Mercado E (2008). New insights into the epidemiology of enteropathogenic Escherichia coli infection. Trans. R. Soc. Trop. Med. Hyg. 102: 852-856. https://doi.org/10.1016/j.trstmh.2008.03.017

Oh KH, Kim SB, Park MS and Cho SH (2014). Development of a one-step PCR assay with nine primer pairs for the detection of five diarrheagenic Escherichia coli types. J. Microbiol. Biotechnol. 24: 862-868. https://doi.org/10.4014/ jmb.1312.12031

Pass MA, Odedra R and Batt RM (2000). Multiplex PCRs for identification of Escherichia coli virulence genes. J. Clin. Microbiol. 38: 2001-2004.

Paton JC and Paton AW (1998). Pathogenesis and diagnosis of Shiga toxin-producing Escherichia coli infections. Clin. Microbiol. Rev. 11: 450-479.

Rumi MV, Irino K, Deza N, Huguet MJ, et al. (2012). First isolation in Argentina of a highly virulent Shiga toxinproducing Escherichia coli O145:NM from a domestic cat. J. Infect. Dev. Ctries. 6: 358-363.

Shen Z, Qu W, Wang W, Lu Y, et al. (2010). MPprimer: a program for reliable multiplex PCR primer design. BMC Bioinformatics 11: 143. https://doi.org/10.1186/1471-2105-11-143

Genetics and Molecular Research 16 (3): gmr16039760 